\title{
Elastic Stress Analysis of Rotating Functionally Graded Annular Disk of Variable Thickness Using Finite Difference Method
}

\author{
Mohammad Hadi Jalali ${ }^{1}{ }^{1}$ and Behrooz Shahriari ${ }^{2}$ \\ ${ }^{1}$ Faculty of Engineering and Applied Science, Memorial University of Newfoundland, St. John's, NL, Canada \\ ${ }^{2}$ Department of Mechanical and Aerospace Engineering, Malek Ashtar University of Technology, Isfahan, Iran \\ Correspondence should be addressed to Mohammad Hadi Jalali; mjalalinodou@mun.ca
}

Received 20 July 2017; Accepted 14 February 2018; Published 25 March 2018

Academic Editor: Fiorenzo A. Fazzolari

Copyright (c) 2018 Mohammad Hadi Jalali and Behrooz Shahriari. This is an open access article distributed under the Creative Commons Attribution License, which permits unrestricted use, distribution, and reproduction in any medium, provided the original work is properly cited.

\begin{abstract}
Elastic stress analysis of rotating variable thickness annular disk made of functionally graded material (FGM) is presented. Elasticity modulus, density, and thickness of the disk are assumed to vary radially according to a power-law function. Radial stress, circumferential stress, and radial deformation of the rotating FG annular disk of variable thickness with clamped-clamped (C-C), clamped-free (C-F), and free-free (F-F) boundary conditions are obtained using the numerical finite difference method, and the effects of the graded index, thickness variation, and rotating speed on the stresses and deformation are evaluated. It is shown that using FG material could decrease the value of radial stress and increase the radial displacement in a rotating thin disk. It is also demonstrated that increasing the rotating speed can strongly increase the stress in the FG annular disk.
\end{abstract}

\section{Introduction}

Functionally graded materials (FGMs) are a type of composite materials that attracted considerable attention in recent years due to their thermomechanical properties. The first idea for producing FGMs was their application in high temperature environment and the improvement of their mechanical properties under complex thermal and mechanical loads. Rotating functionally graded disks find their application in ship propellers, aerospace structures, flywheels, and internal combustion engines. In many of these applications, the structure is under sever mechanical loading and the material can operate under such severe loadings [1-4].

Lamb and Southwell [5] for the first time investigated the vibrations of spinning disk. They obtained the natural frequencies of rotating, homogenous, constant thickness circular disk using exact solution. Southwell [6] extended the Lamb's work and analyzed the effects of rotation on the vibrations of uniform homogeneous circular disk, more deeply. Deshpande and Mote [7] presented a model for inplane vibration of rotating thin disk. Their model accounts for the stiffening of the disk due to the radial expansion resulting from its rotation. Asghari and Ghafoori [8] presented a 3D semianalytical solution for obtaining elasticity response of the rotating FG disks. They investigated effect of various parameters on the stresses and radial deformation.

Lee and $\mathrm{Ng}$ [9] used the assumed modes method to formulate the equations of motion of rotating homogeneous annular plates. They assumed the thickness of the plate to vary linearly and exponentially and they obtained the natural frequencies and critical speeds for vibration modes. Shahriari et al. [10] applied generalized differential quadrature method (GDQM) for studying free vibration of rotating disk with attached rigid blades. They obtained the natural frequencies and critical speeds of a rotating bladed disk that can be used in real aircraft gas turbine engine. Kermani et al. [11] used differential quadrature method (DQM) to solve the equations of motion of rotating FG annular plates. They obtained the natural frequencies and critical speeds of the plates and evaluated the effects of the graded index, angular velocity, and geometric parameters on the modal data. Jalali et al. [12] studied the free vibration of rotating FG disk of variable thickness using GDQ method. They evaluated the effects of geometrical and material properties of the rotating FG disk on the natural frequencies and critical speeds. 
Nie and Batra [13] investigated the stress of the isotropic, linear thermoelastic, and incompressible FG rotating disks of variable thickness. They solved the ordinary differential equation analytically and also numerically by the DQ method. Zafarmand and Hassani [14] used graded finite element method to study the stress in rotating FG circular thick disks with variable thickness. They investigated the displacements and stress for four different thickness profiles. Bayat et al. [15] solved the equations of motion of rotating disks of variable thickness by a semianalytical method and also by an exact solution. In the semianalytical method, they assumed that the disk consists of some rings. The variation of the mechanical properties and thickness of the plate were graded by powerlaw function in their paper. Çallioğlu et al. [16] analyzed the stress of uniform FG rotating disks, numerically and analytically. They used finite element method and Ansys software to obtain the radial and circumferential stress and radial displacement of rotating FG disks and compared the numerical results with the results obtained analytically. They also investigated the effects of the graded index on the stresses and displacements. Gutzwiller and Turner [17, 18] developed computer software for automated design optimization of rotating bladed disks. They used finite difference method for obtaining the stresses and displacements and they assumed various thickness variations of the plate in their research.

Carrera et al. [19] proposed a 1D FE method for 3D thermoelastic analysis of rotating disk with variable thickness. They considered four types of temperature variation along the radius of the disk and validated their results through comparing them with those of finite difference method and analytical method. Kouchakzadeh and Entezari [20] and Entezari and Kouchakzadeh [21] presented analytical solutions for the problem of generalized coupled thermoelasticity in rotating disks subjected to mechanical and thermal shock loads. Vivio et al. [22] carried out a stress analysis in rotating disk without singularities and with temperature distribution along the radial direction. They assumed the thickness variation of the disk to be hyperbolic and solved the equation analytically.

To the best of the author's knowledge, elastic stress analysis of rotating functionally graded annular disks has not been performed in the literature. In this paper, finite difference method is used for solving the equations of motion of rotating FG annular plates with variable thickness. The variation of Young's modulus, density, and thickness of the disk in radial direction are assumed to be graded by power-law function. The equations of motion are obtained considering the plane stress condition. The boundary conditions of the disk are assumed to be (C-C), (C-F), and (F-F). The effects of the graded index, thickness variation, and angular velocity on the radial and circumferential stress and radial displacement are evaluated.

\section{Governing Equations}

An annular FG plate with outer radius $a$, inner radius $b$, thickness $t$, and outer surface thickness $h_{0}$, which is rotating with angular velocity $\widetilde{\omega}$, is shown in Figure 1 . As can be seen, thickness $t$ is variable in the radial direction.

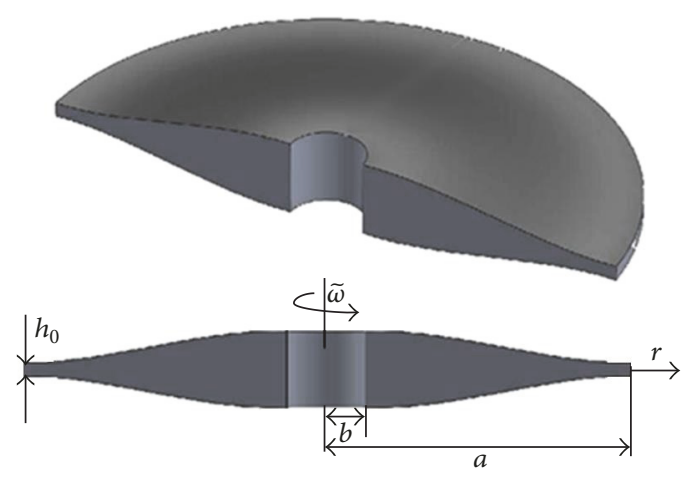

FIGURE 1: Rotating annular FG plate.

The plane stress equilibrium equation in the radial direction by considering the variation of the thickness is

$$
\frac{d}{d r}\left(t r \sigma_{r}\right)-t \sigma_{\theta}+t \rho \widetilde{\omega}^{2} r^{2}=0
$$

where $\sigma_{r}$ is the radial stress, $\sigma_{\theta}$ is the circumferential stress, $t$ is the thickness, $\widetilde{\omega}$ is rotating speed of the plate, and $\rho$ is the density. By considering that the plate is axisymmetric $(\partial / \partial \theta=$ 0 ), the Kirchhoff strain-displacement relations become as follows:

$$
\begin{aligned}
\varepsilon_{r} & =\frac{d u}{d r}, \\
\varepsilon_{\theta} & =\frac{u}{r}, \\
\gamma_{r \theta} & =0,
\end{aligned}
$$

where $u$ is the radial displacement. The stress-strain relations are given by

$$
\begin{gathered}
\sigma_{r}=\frac{E}{1-v^{2}}\left(\varepsilon_{r}+v \varepsilon_{\theta}\right), \\
\sigma_{\theta}=\frac{E}{1-v^{2}}\left(v \varepsilon_{r}+\varepsilon_{\theta}\right),
\end{gathered}
$$

where $E$ is Young's modulus and $v$ is Poisson ratio which is assumed to be constant. By substituting (2) in (3), stresses are obtained in terms of radial displacement:

$$
\begin{gathered}
\sigma_{r}=\frac{E}{1-v^{2}}\left(\frac{d u}{d r}+\frac{v u}{r}\right), \\
\sigma_{\theta}=\frac{E}{1-v^{2}}\left(\frac{v d u}{d r}+\frac{u}{r}\right) .
\end{gathered}
$$

Also, we can rewrite (4) in the following form:

$$
\begin{aligned}
& \sigma_{r}=A \frac{d u}{d r}+B \frac{u}{r}, \\
& \sigma_{\theta}=B \frac{d u}{d r}+C \frac{u}{r},
\end{aligned}
$$

where $A, B, C$ are the stiffness terms and can be found easily. By substituting (5) in to (1), the equilibrium equation 
is obtained in terms of radial displacement and the obtained equation should be solved by considering the boundary conditions. Equations (6)-(8) present the boundary condition equations for (C-C), (C-F), and (F-F) boundary conditions, respectively.

Clamped-Clamped (C-C)

$$
\begin{array}{ll}
u=0 & r=b, \\
u=0 & r=a .
\end{array}
$$

Clamped-Free (C-F)

$$
\begin{array}{cc}
u=0 & r=b, \\
\sigma_{r}=0 & r=a .
\end{array}
$$

Free-Free $(F-F)$

$$
\begin{array}{ll}
\sigma_{r}=0 & r=b, \\
\sigma_{r}=0 & r=a .
\end{array}
$$

\section{Finite Difference Method}

In the finite difference method, the disk is discretized along $(N)$ radial stations. The method consists of developing an expression for radial stress using three consecutive points [18]. At the end of the process, there are $N-2$ equations for the inner points and two known radial stress boundary equations for the inner and outer surface of the disk. The radial displacements are the unknown variables in the final $N \times N$ matrix equation [18]. In this paper, the stiffness terms $(A, B, C)$, thickness $(t)$, stresses $(\sigma)$, and displacement $(u)$ are the functions of radius $(r)$ because Young's modulus is dependent on radius. Figure 2 shows the numbering scheme used in the method.

The radial stress can be estimated over intervals [1-2] and [0-1] from (5) [18]:

$$
\begin{aligned}
& \bar{\sigma}_{r 10}=\frac{\sigma_{r 0}+\sigma_{r 1}}{2}=\bar{A}_{10} \frac{u_{1}-u_{0}}{r_{1}-r_{0}}+\bar{B}_{10} \frac{\bar{u}_{10}}{\bar{r}_{10}}, \\
& \bar{\sigma}_{r 21}=\frac{\sigma_{r 1}+\sigma_{r 2}}{2}=\bar{A}_{21} \frac{u_{2}-u_{1}}{r_{2}-r_{1}}+\bar{B}_{21} \frac{\bar{u}_{21}}{\bar{r}_{21}},
\end{aligned}
$$

where

$$
\begin{aligned}
& \bar{A}_{p q}=\frac{A_{p}+A_{q}}{2}, \\
& \bar{B}_{p q}=\frac{B_{p}+B_{q}}{2}, \\
& \bar{u}_{p q}=\frac{u_{p}+u_{q}}{2}, \\
& \bar{r}_{p q}=\frac{r_{p}+r_{q}}{2},
\end{aligned}
$$

where $p=2,1$ and $q=1,0$. Similar expressions can be written for $\sigma_{\theta}$.

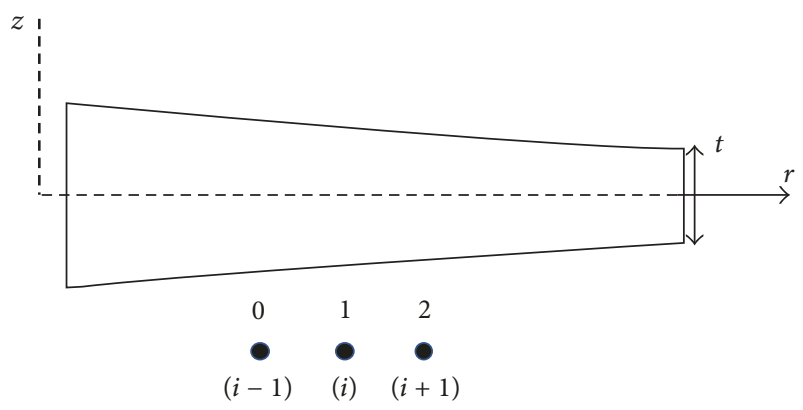

FIGURE 2: Numbering scheme in radial direction.

By integrating (1) and the second equation of (5) over intervals [1-2] and [0-1] and using the above expressions,

$$
\begin{aligned}
\left(\operatorname{tr} \sigma_{r}\right)_{2}-\left(\operatorname{tr} \sigma_{r}\right)_{1}= & \bar{t}_{21} \bar{\sigma}_{\theta 21}\left(r_{2}-r_{1}\right) \\
& -\bar{t}_{21} \bar{\rho}_{21} \widetilde{\omega}^{2}\left(\frac{r_{2}^{3}-r_{1}^{3}}{3}\right), \\
\left(\operatorname{tr} \sigma_{r}\right)_{1}-\left(\operatorname{tr} \sigma_{r}\right)_{0}= & \bar{t}_{10} \bar{\sigma}_{\theta 10}\left(r_{1}-r_{0}\right) \\
& -\bar{t}_{10} \bar{\rho}_{10} \widetilde{\omega}^{2}\left(\frac{r_{1}^{3}-r_{0}^{3}}{3}\right), \\
\bar{\sigma}_{\theta 21}\left(r_{2}-r_{1}\right)= & \bar{B}_{21}\left(u_{2}-u_{1}\right)+\bar{C}_{21} \bar{u}_{21} \ln \left(\frac{r_{2}}{r_{1}}\right), \\
\bar{\sigma}_{\theta 10}\left(r_{1}-r_{0}\right)= & \bar{B}_{10}\left(u_{1}-u_{0}\right)+\bar{C}_{10} \bar{u}_{10} \ln \left(\frac{r_{1}}{r_{0}}\right),
\end{aligned}
$$

where

$$
\begin{aligned}
& \bar{t}_{p q}=\frac{t_{p}+t_{q}}{2}, \\
& \bar{\rho}_{p q}=\frac{\rho_{p}+\rho_{q}}{2}, \\
& \quad p=2,1, q=1,0 .
\end{aligned}
$$

Now, we can develop expressions for $\sigma_{r 1}$ in intervals [1-2] and [0-1]. By omitting $\sigma_{r 2}$ from (10) and (12) and substituting (14) in the resulting equation, the following expression for $\sigma_{r 1}$ in terms of known quantities in the interval [1-2] is obtained:

$$
\begin{aligned}
\sigma_{r 1} & =\frac{2 t_{2} r_{2}}{t_{2} r_{2}+t_{1} r_{1}}\left(\bar{A}_{21} \frac{u_{2}-u_{1}}{r_{2}-r_{1}}+\bar{B}_{21} \frac{\bar{u}_{21}}{\bar{r}_{21}}\right) \\
& +\frac{\bar{t}_{21}}{t_{2} r_{2}+t_{1} r_{1}}\left(-\bar{B}_{21}\left(u_{2}-u_{1}\right)-\bar{C}_{21} \bar{u}_{21} \ln \left(\frac{r_{2}}{r 1}\right)\right. \\
& \left.+\bar{\rho}_{21} \widetilde{\omega}^{2}\left(\frac{r_{2}^{3}-r_{1}^{3}}{3}\right)\right) .
\end{aligned}
$$


Also, by omitting $\sigma_{r 0}$ from (9) and (13) and substituting (15) in the resulting equation, the following expression for $\sigma_{r 1}$ in the interval [0-1] is obtained [18]:

$$
\begin{aligned}
\sigma_{r 1} & =\frac{2 t_{0} r_{0}}{t_{1} r_{1}+t_{0} r_{o}}\left(\bar{A}_{10} \frac{u_{1}-u_{0}}{r_{1}-r_{o}}+\bar{B}_{10} \frac{\bar{u}_{10}}{\bar{r}_{10}}\right) \\
& +\frac{\bar{t}_{10}}{t_{1} r_{1}+t_{0} r_{o}}\left(\bar{B}_{10}\left(u_{1}-u_{0}\right)+\bar{C}_{10} \bar{u}_{10} \ln \left(\frac{r_{1}}{r_{0}}\right)\right. \\
& \left.-\bar{\rho}_{10} \widetilde{\omega}^{2}\left(\frac{r_{1}^{3}-r_{0}^{3}}{3}\right)\right) .
\end{aligned}
$$

By equating the right side of (18) and (17) and substituting $u_{i+1}, u_{i}, u_{i-1}$, an equation with unknowns $u_{i+1}, u_{i}, u_{i-1}$ can be obtained. The following equation leads to a system of $(N-2)$ equations. The two remaining equations come from the discretization of the boundary conditions:

$$
\begin{aligned}
& {\left[\frac{2 t_{0} r_{0}}{t_{0} r_{0}+t_{1} r_{1}}\left(\frac{\bar{A}_{10}}{r_{1}-r_{0}}-\frac{\bar{B}_{10}}{2 \bar{r}_{10}}\right)\right.} \\
& \left.+\frac{\bar{t}_{10}}{t_{0} r_{0}+t_{1} r_{1}}\left(\bar{B}_{10}-\frac{\bar{C}_{10}}{2} \ln \left(\frac{r_{1}}{r_{0}}\right)\right)\right] u_{i-1} \\
& +\left[\frac{2 t_{2} r_{2}}{t_{2} r_{2}+t_{1} r_{1}}\left(\frac{-\bar{A}_{21}}{r_{2}-r_{1}}+\frac{\bar{B}_{21}}{2 \bar{r}_{21}}\right)\right. \\
& +\frac{\bar{t}_{21}}{t_{2} r_{1}+t_{1} r_{1}}\left(\bar{B}_{21}-\frac{\bar{C}_{21}}{2} \ln \left(\frac{r_{2}}{r_{1}}\right)\right) \\
& -\frac{2 t_{o} r_{o}}{t_{o} r_{o}+t_{1} r_{1}}\left(\frac{\bar{A}_{10}}{r_{1}-r_{o}}+\frac{\bar{B}_{10}}{2 \bar{r}_{10}}\right) \\
& \left.-\frac{\bar{t}_{10}}{t_{0} r_{0}+t_{1} r_{1}}\left(\bar{B}_{10}+\frac{\bar{C}_{10}}{2} \ln \left(\frac{r_{1}}{r_{0}}\right)\right)\right] u_{i} \\
& +\left[\frac{2 t_{2} r_{2}}{t_{2} r_{2}+t_{1} r_{1}}\left(\frac{\bar{A}_{21}}{r_{2}-r_{1}}+\frac{\bar{B}_{21}}{2 \bar{r}_{21}}\right)\right. \\
& \left.-\frac{\bar{t}_{21}}{t_{2} r_{2}+t_{1} r_{1}}\left(\bar{B}_{21}+\frac{\bar{C}_{21}}{2} \ln \left(\frac{r_{2}}{r_{1}}\right)\right)\right] u_{i+1} \\
& =\frac{\bar{t}_{21} \bar{\rho}_{21} \widetilde{\omega}^{2}}{t_{1} r_{1}+t_{2} r_{2}}\left(\frac{r_{2}^{3}-r_{1}^{3}}{3}\right)-\frac{\bar{t}_{10} \bar{\rho}_{10} \widetilde{\omega}^{2}}{t_{0} r_{0}+t_{1} r_{1}}\left(\frac{r_{1}^{3}-r_{0}^{3}}{3}\right) \text {. }
\end{aligned}
$$

In order to obtain the two remaining equations, the boundary conditions should be discretized. For the clamped boundary condition in inner or outer surfaces, the radial displacement in boundary surfaces should be zero. Thus, the boundary equations for (C-C) boundary conditions are as follows.

\section{Clamped-Clamped (C-C)}

$$
\begin{array}{cc}
u_{1}=0 & r=b, \\
u_{N}=0 & r=a .
\end{array}
$$

By applying the displacements of nodal points $(N-2),(N-1)$, $(N)$ and the displacement of nodal points $1,2,3$ to (5), the boundary equations are as follows.

Clamped-Free (C-F)

$$
\begin{aligned}
& u_{1}=0 \quad r=b, \\
& \sigma_{r}=A_{N}\left(\frac{3 u_{N}-4 u_{N-1}+u_{N-2}}{r_{N}-r_{N-2}}\right)+B_{N} \frac{u_{N}}{r_{N}}=0 \Longrightarrow \\
& \left(\frac{A_{N}}{r_{N}-r_{N-2}}\right) u_{N-2}+\left(\frac{-4 A_{N}}{r_{N}-r_{N-2}}\right) u_{N-1} \\
& \quad+\left(\frac{B_{N}}{r_{N}}+\frac{3 A_{N}}{r_{N}-r_{N-2}}\right) u_{N}=0
\end{aligned}
$$

$$
r=a \text {. }
$$

Free-Free $(F-F)$

$$
\begin{aligned}
& \sigma_{r}=A_{1}\left(\frac{4 u_{2}-u_{3}-3 u_{1}}{r_{3}-r_{1}}\right)+B_{1} \frac{u_{1}}{r_{1}}=0 \Longrightarrow \\
& \left(\frac{B_{1}}{r_{1}}-\frac{3 A_{1}}{r_{3}-r_{1}}\right) u_{1}+\left(\frac{4 A_{1}}{r_{3}-r_{1}}\right) u_{2}+\left(\frac{-A_{1}}{r_{3}-r_{1}}\right) u_{3} \\
& =0 \\
& \left(\frac{A_{N}}{r_{N}-r_{N-2}}\right) u_{N-2}+\left(\frac{-4 A_{N}}{r_{N}-r_{N-2}}\right) u_{N-1} \\
& +\left(\frac{B_{N}}{r_{N}}+\frac{3 A_{N}}{r_{N}-r_{N-2}}\right) u_{N}=0 \quad r=a .
\end{aligned}
$$

The discussed discretization leads to system of $N$ linear equations with the radial displacement $(u)$ as the unknown variable. Once the radial displacement in nodal points is calculated, radial stress in each point can be obtained using (17) or (18).

The boundary values for tangential stress can be obtained by (25) which are similar to (22) and (23) for radial stress boundary values. Once the radial displacements in all the points are calculated, the boundary tangential stress values can be obtained using (25) and tangential stress values in the inner points of the disk can be obtained using (14) or (15).

$$
\begin{aligned}
& \sigma_{\theta}=B_{1}\left(\frac{4 u_{2}-u_{3}-3 u_{1}}{r_{3}-r_{1}}\right)+D_{1} \frac{u_{1}}{r_{1}} \quad r=b, \\
& \sigma_{\theta}=B_{N}\left(\frac{3 u_{N}-4 u_{N-1}+u_{N-2}}{r_{N}-r_{N-2}}\right)+D_{N} \frac{u_{N}}{r_{N}} \quad r=a .
\end{aligned}
$$

Young's modulus, density, and thickness of the disk are varied in radial direction using the following power-law functions:

$$
E=E_{0}\left(\frac{r}{a}\right)^{n}
$$




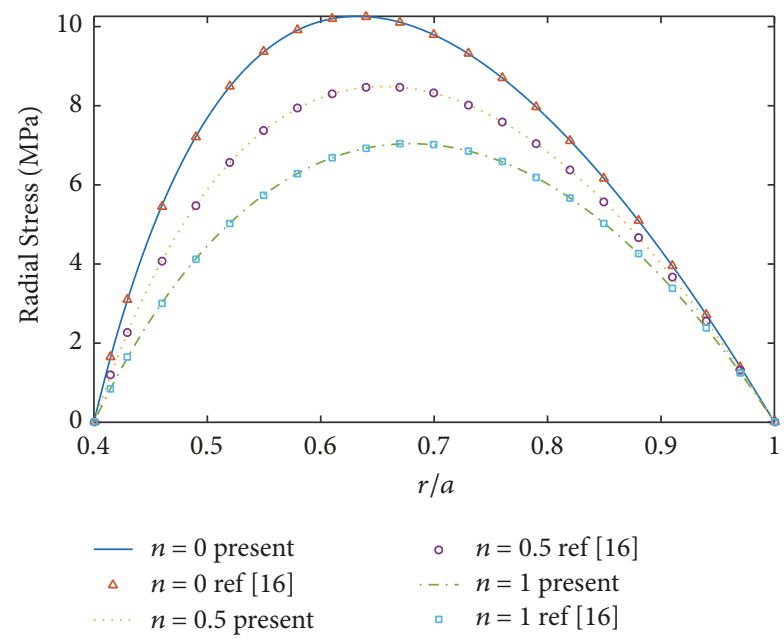

FIGURE 3: Variation of radial stress versus radius with (F-F) boundary conditions $(\alpha=0)$.

$$
\begin{aligned}
& \rho=\rho_{0}\left(\frac{r}{a}\right)^{n}, \\
& t=h_{0}\left(\frac{r}{a}\right)^{\alpha},
\end{aligned}
$$

where $n$ is the graded index and $\alpha$ is the parameter for the variation of the thickness in radial direction.

\section{Numerical Results}

For the numerical stress analysis, the inner and outer radii of the plate are $b=0.04 \mathrm{~m}$ and $a=0.1 \mathrm{~m}$. The thickness in the outer surface is $h_{0}=0.005 \mathrm{~m} ; E_{0}=72000 \mathrm{MPa}$ and $\rho_{0}=2800 \mathrm{~kg} / \mathrm{m}^{3}$ are the assumed Young's modulus and density in the outer surface, respectively. The angular velocity is assumed to be $15000 \mathrm{rpm}$.

Figure 3 shows the variation of radial stress $\left(\sigma_{r}\right)$ in the radial direction of rotating uniform disk with (F-F) boundary conditions for $n=0, n=0.5, n=1$. As it should be, $\sigma_{r}$ in the inner and outer radii is zero. As it is obvious from the figure, there is a good agreement between the present results and results obtained in [16], in which the solution is obtained by numerical and analytical methods. It can be seen that using FG material can reduce the values of radial stress in rotating disks because radial stress has lower value for $n=1$ and $n=0.5$ when compared with the results for $n=0$. Also, it can be observed that the location of maximum stress in the disk shifts toward the outer surface for the FG material with $n=0.5$ and $n=1$. Figure 4 shows the circumferential stress variation in the radial direction of rotating uniform disk and Figure 5 shows the radial displacement of the disk for various values of graded index. It also shows good agreement between the results in [16].

It can be seen that for $n=1$, the radial displacement is larger than the radial displacement for $n=0.5$ and the radial displacement for $n=0.5$ is larger than the radial displacement for $n=0$. It shows that, by using FG material, the radial displacement can increase.

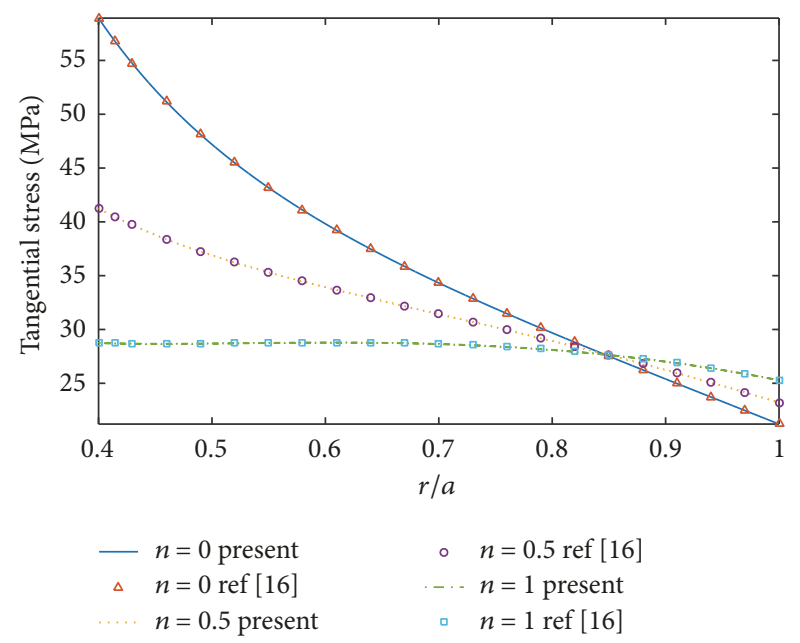

FIGURE 4: Variation of circumferential stress versus radius with (FF) boundary conditions $(\alpha=0)$.

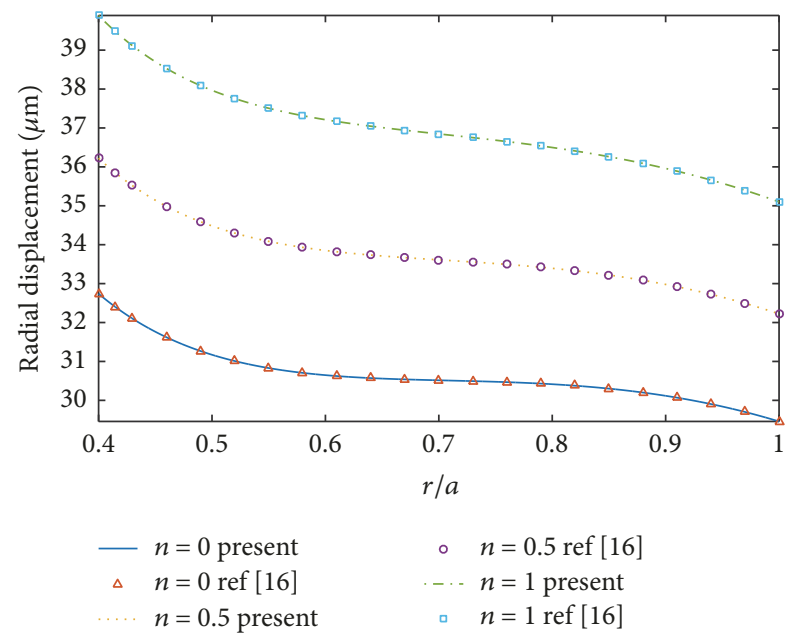

FIGURE 5: Variation of radial displacement versus radius with (F-F) boundary conditions $(\alpha=0)$.

Figures 6 and 7 show the variation of radial stress and circumferential stress in radial direction of uniform disk for (C-C) boundary conditions for $n=0, n=0.5$, and $n=1$, respectively. As it can be seen from the figures, $\sigma_{r}$ and $\sigma_{\theta}$ decrease gradually with an increase in the graded index.

Figure 8 shows the radial displacement of rotating uniform disk for (C-C) boundary conditions for different values of graded index. The values of radial displacement increase gradually with an increase in the graded index.

In Figures 9-11, the same results are shown for (C-F) boundary conditions. It can be shown that the effect of the graded index on the stresses is independent of the type of the boundary conditions.

In Figures 12 and 13, the variation of radial stress and circumferential stress in rotating disk with (F-F) boundary conditions and with different thickness profiles are shown. In these figures, the disk is assumed to be homogeneous $(n=$ 0 ). According to (28), when $\alpha=0$, the disk has constant 

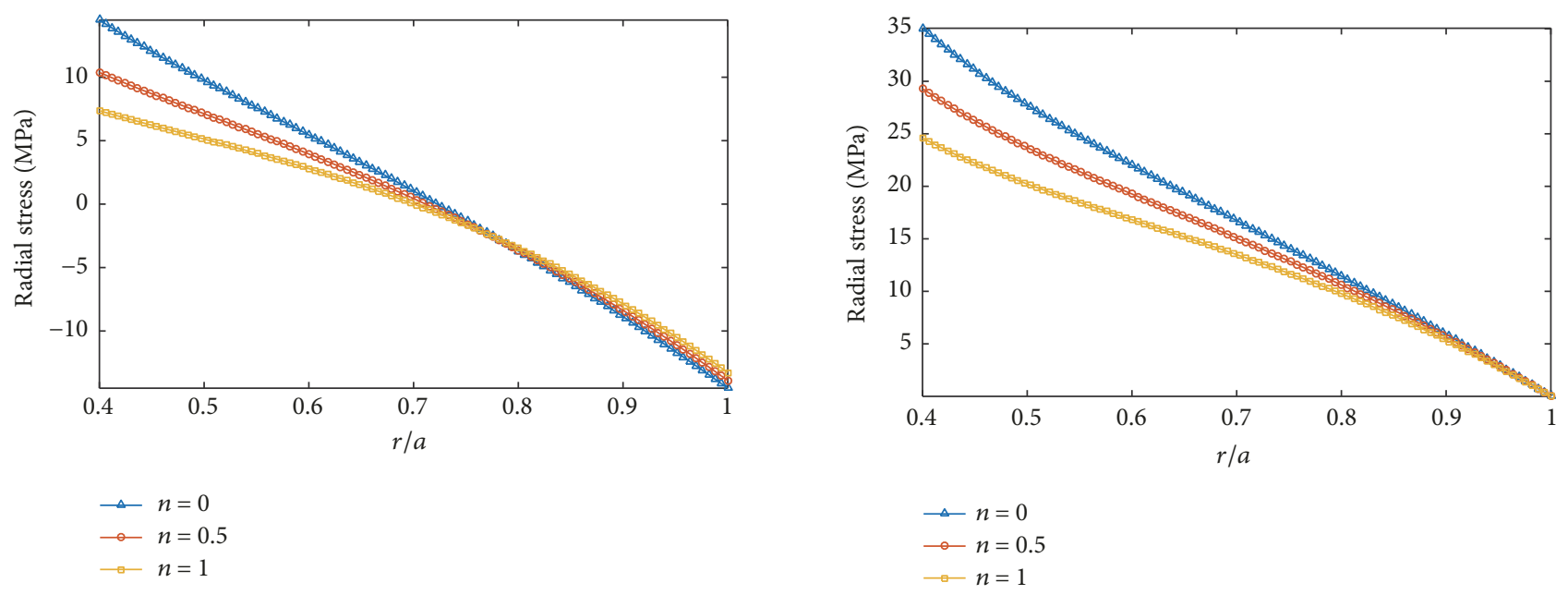

FIGURE 6: Variation of radial stress versus radius, (C-C) $(\alpha=0)$.

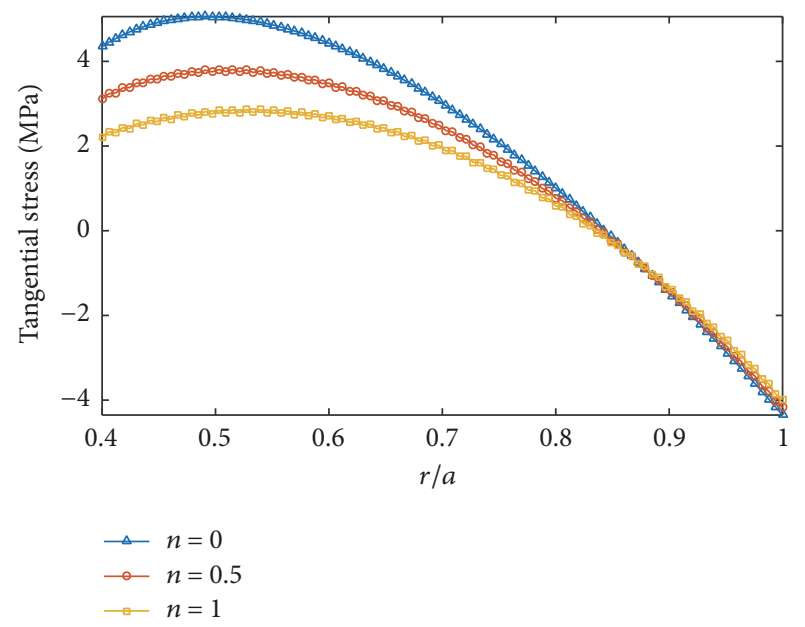

FIGURE 7: Variation of circumferential stress versus radius, (C-C) $(\alpha=0)$.

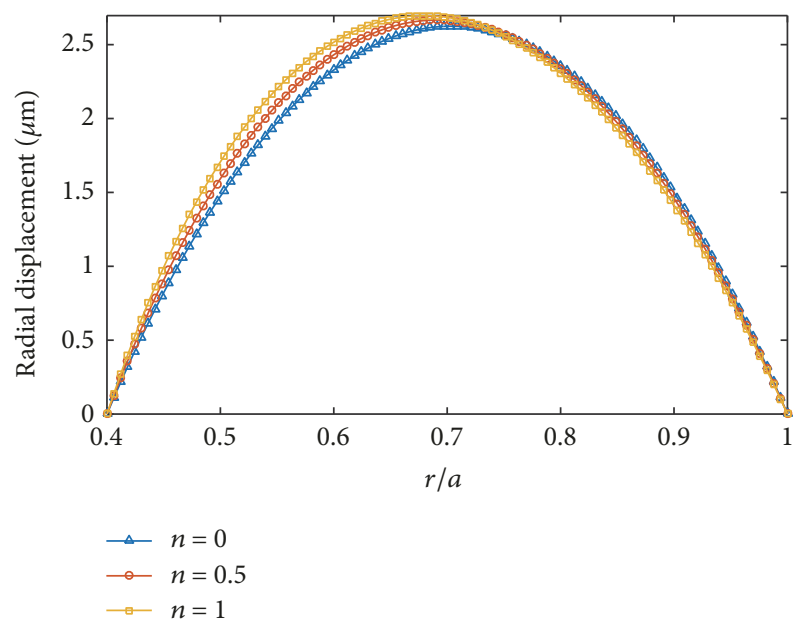

FIGURE 8: Variation of radial displacement versus radius, (C-C) $(\alpha=$ $0)$.

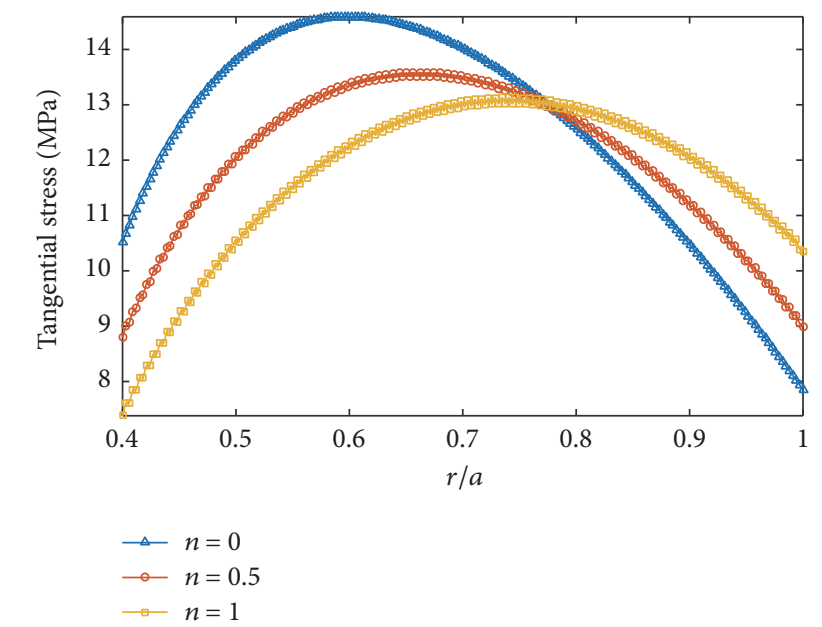

FIgURE 10: Variation of circumferential stress versus radius, (C-F) $(\alpha=0)$.

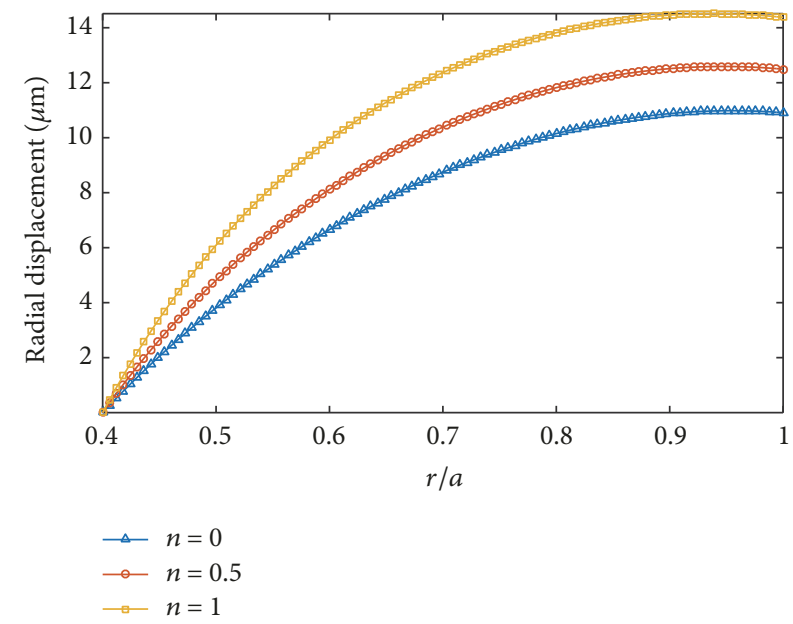

FIGURE 11: Variation of radial displacement versus radius, (C-F) $(\alpha=$ $0)$. 


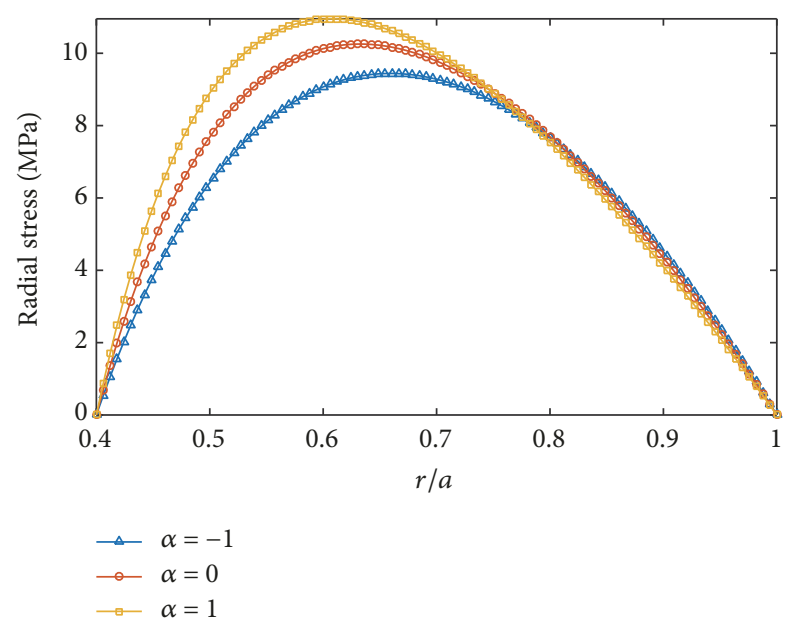

FIGURE 12: Variation of radial stress versus radius with different thickness profiles, (F-F) $(n=0)$.

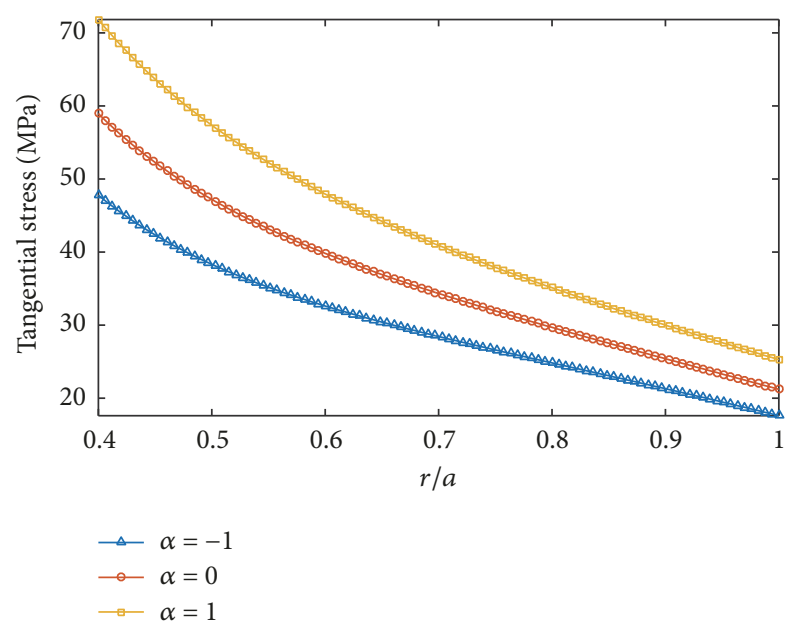

FIGURE 13: Variation of circumferential stress versus radius with different thickness profiles, (F-F) $(n=0)$.

thickness; when $\alpha=-1$, it resembles a disk whose thickness decreases parabolically with increase in radius; and when $\alpha=$ 1 , it resembles a disk whose thickness varies linearly in radial direction. As can be observed, the values of stresses for $\alpha=1$ are larger than the values of stresses for $\alpha=0$ and the values of stresses for $\alpha=0$ are larger than the values of stresses for $\alpha=-1$. It shows that, by using a disk whose thickness decreases toward the outer surface, we can have lower values of stress in the rotating disk.

Figure 14 shows the variation of radial displacement in the same disk. It can be observed that the values of radial displacement increase gradually with the increase in $\alpha$. It means that, by using a linearly variable thickness disk, the radial displacement is larger than the radial displacement in the other two cases.

Figures $15-17$ and Figures 18-20 show the radial stress, circumferential stress, and radial displacement for rotating homogeneous disk with (C-F) and (C-C) boundary conditions, respectively. As can be seen from these figures, the

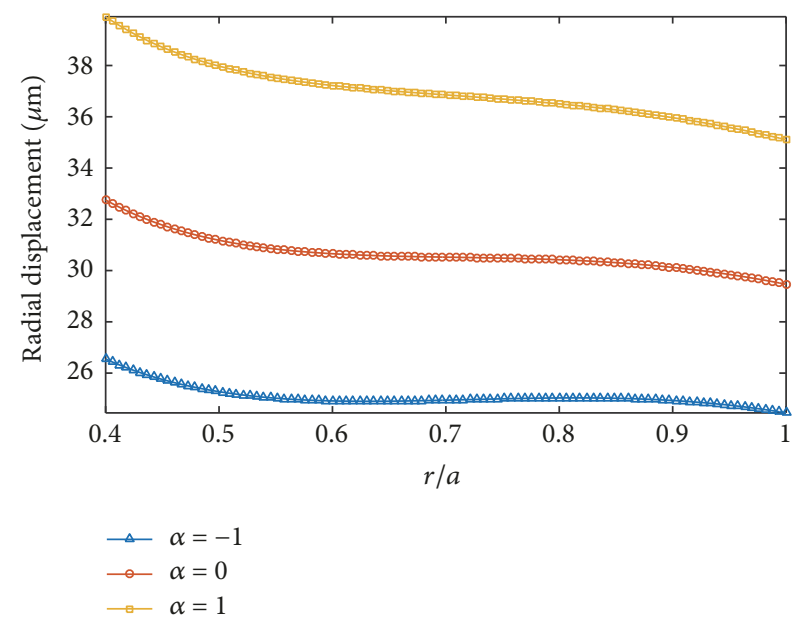

FIGURE 14: Variation of radial displacement versus radius with different thickness profiles, (F-F) $(n=0)$.

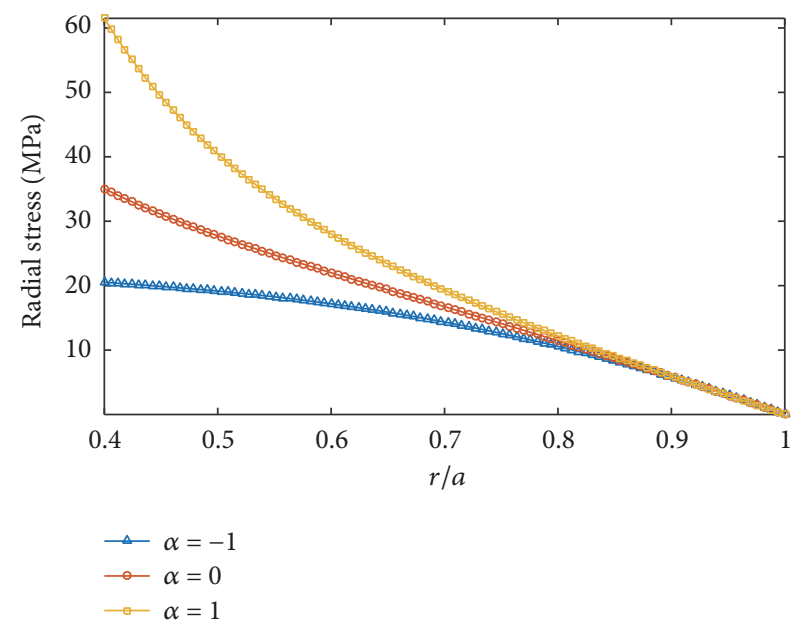

FIGURE 15: Variation of radial stress versus radius, $(\mathrm{C}-\mathrm{F})(n=0)$.

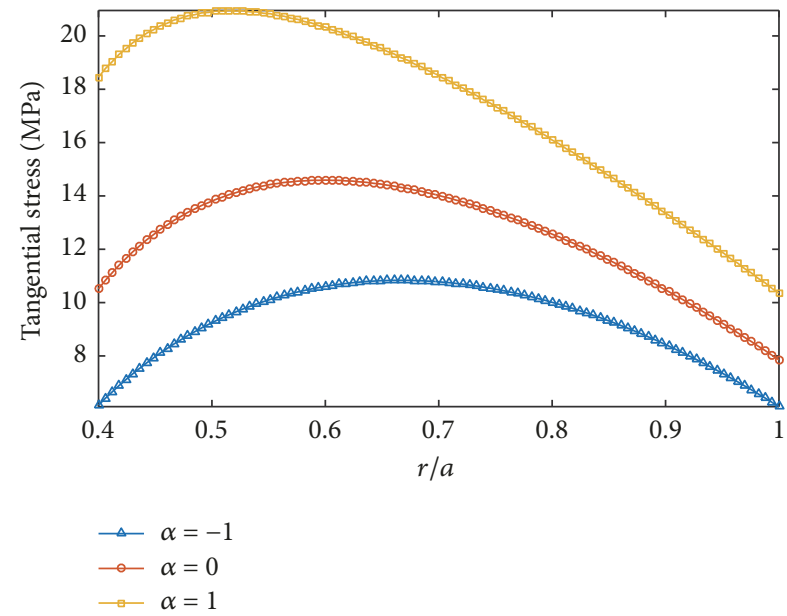

Figure 16: Variation of tangential stress versus radius, $(\mathrm{C}-\mathrm{F})(n=0)$. 


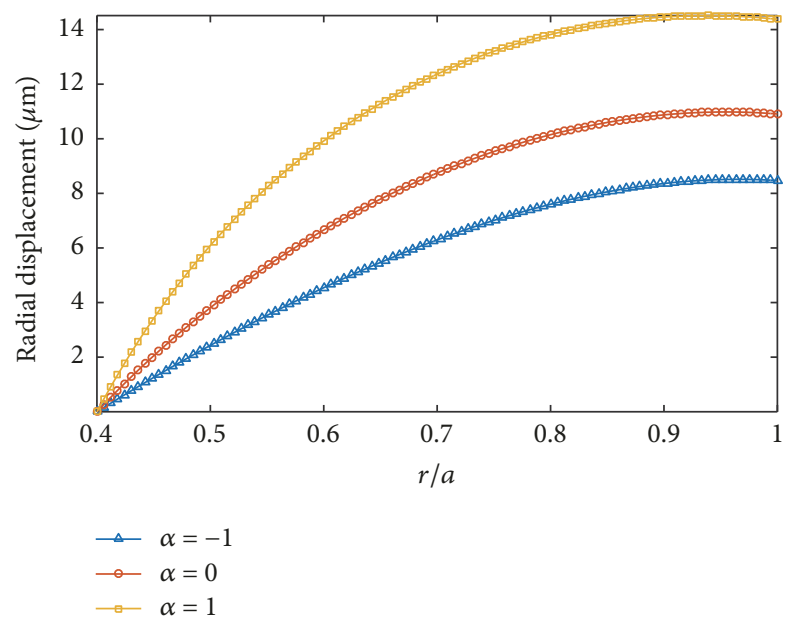

FigurE 17: Variation of radial displacement versus radius, $(\mathrm{C}-\mathrm{F})(n=$ $0)$.

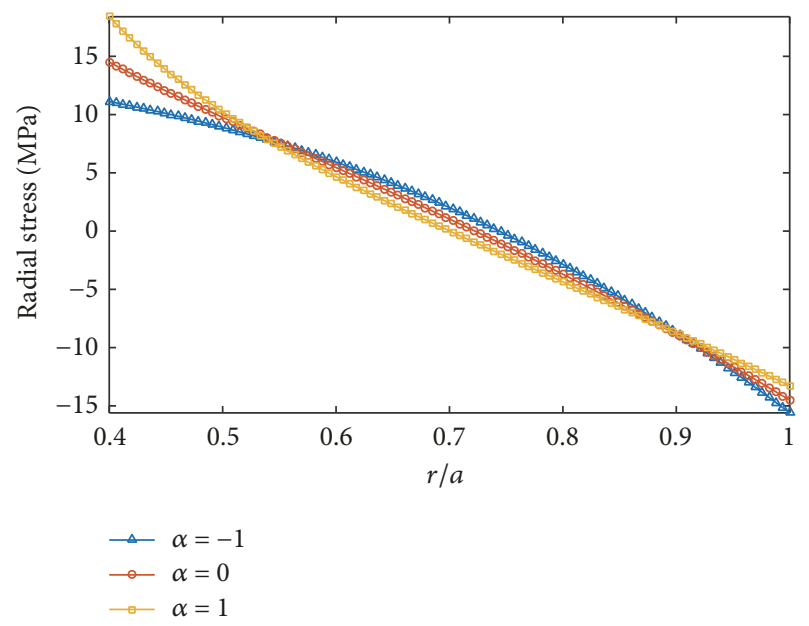

FIGURE 18: Variation of radial stress versus radius, (C-C) $(n=0)$.

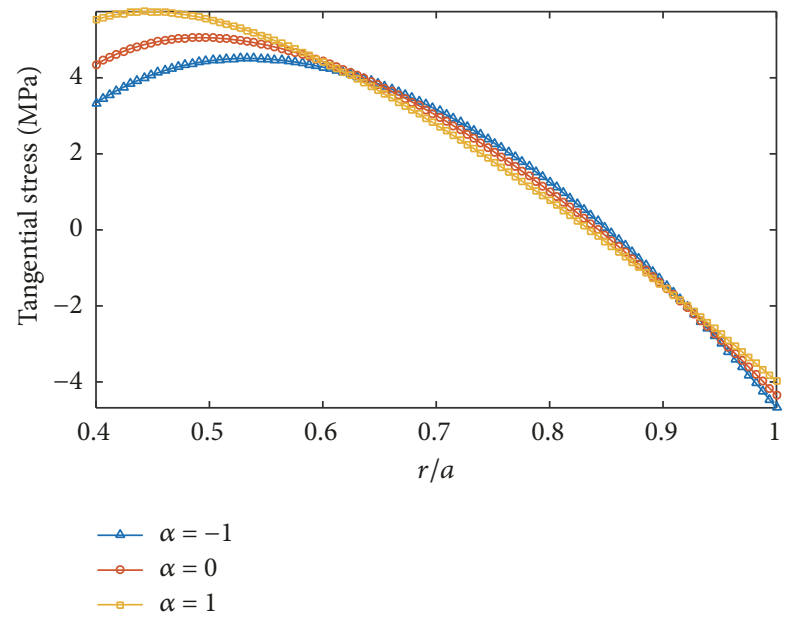

FIGURE 19: Variation of circumferential stress versus radius, (C-C) $(n=0)$.

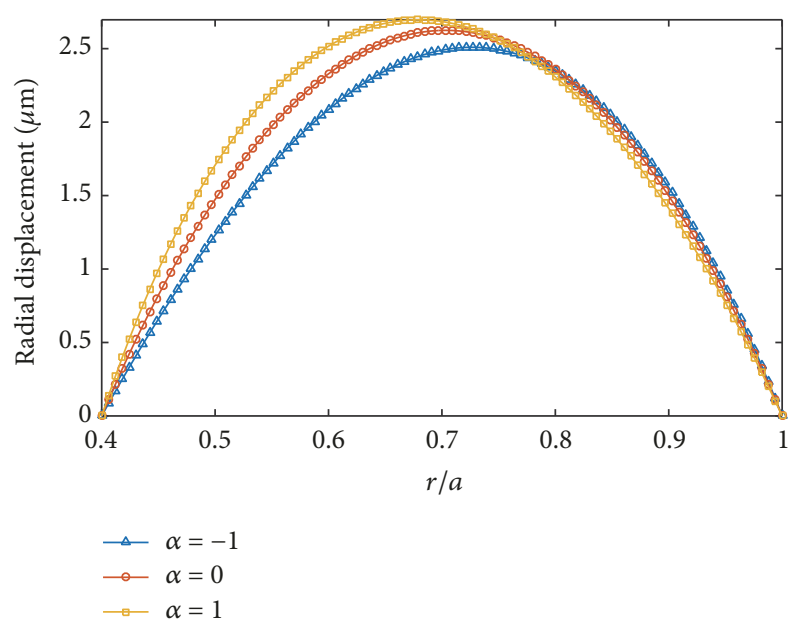

FIGURE 20: Variation of radial displacement versus radius, (C-C) $(n=0)$.

stresses and radial displacement in the disk whose thickness decreases toward the outer surface are lower than the other two cases of thickness variations.

Figures 21-23 show the variation of stresses and displacement in radial direction for (F-F), (C-F), and (C-C) boundary conditions, respectively. In these figures, the graded index $(n)$ is assumed to be $n=1$. It can be seen from the figures that, by using linear variable thickness disk, we have the largest radial displacement and stresses.

The results for the effect of the thickness variation on stresses and displacement for disks with $n=0$ and $n=1$ are the same as each other. It can be concluded that these results are independent of the value of the graded index.

In Figure 24, the variation of radial stress of a rotating FG disk for different values of rotating speed is shown. As it is expected, the radial stress increases significantly with the increase in the rotating speed.

\section{Conclusions}

In this paper, the numerical finite difference method is used to solve the equations of motion of rotating annular variable thickness disk made of functionally graded materials. Radial and circumferential stresses and radial displacement for both edges clamped (C-C), inner edge clamped, outer edge free $(\mathrm{C}-\mathrm{F})$, and both edges free (F-F) boundary conditions were obtained. The effects of various geometric and material properties on the stresses and radial deflection were investigated. The following results are the summary of the most important results of the paper.

(1) It was demonstrated that using FG material could decrease the value of radial and circumferential stress and increase the radial displacement in a rotating thin disk.

(2) The effects of the thickness variation on the stresses and radial displacement were evaluated. It was shown that, by using linear variable thickness disk, we have the largest radial displacement and stresses. 


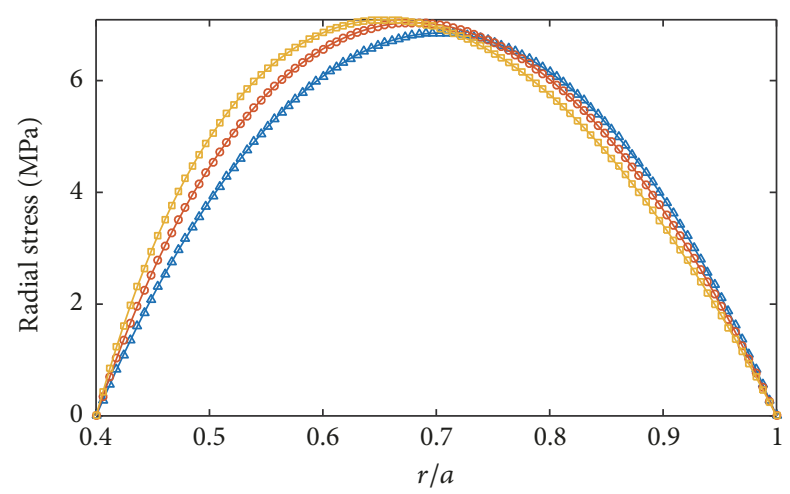

$$
\begin{aligned}
& \therefore \alpha=-1 \\
& \because \alpha=0 \\
& \because \alpha=1
\end{aligned}
$$

(a)

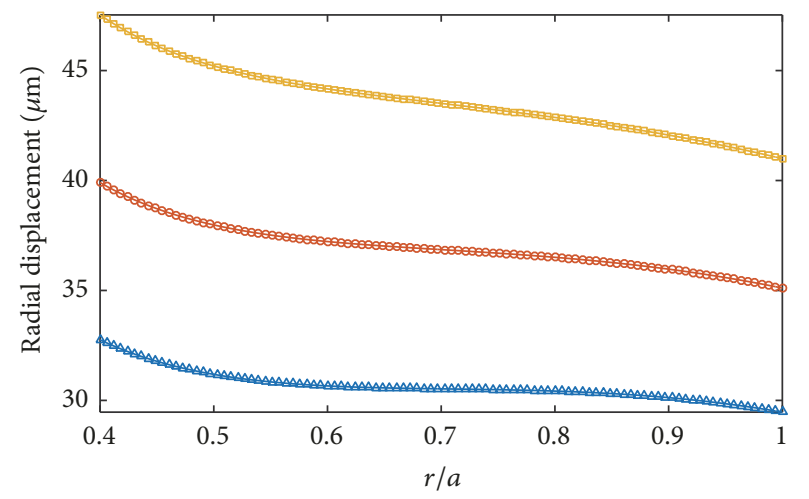

$$
\begin{aligned}
& \rightarrow \alpha=-1 \\
& \multimap \alpha=0 \\
& -\alpha=1
\end{aligned}
$$

(b)

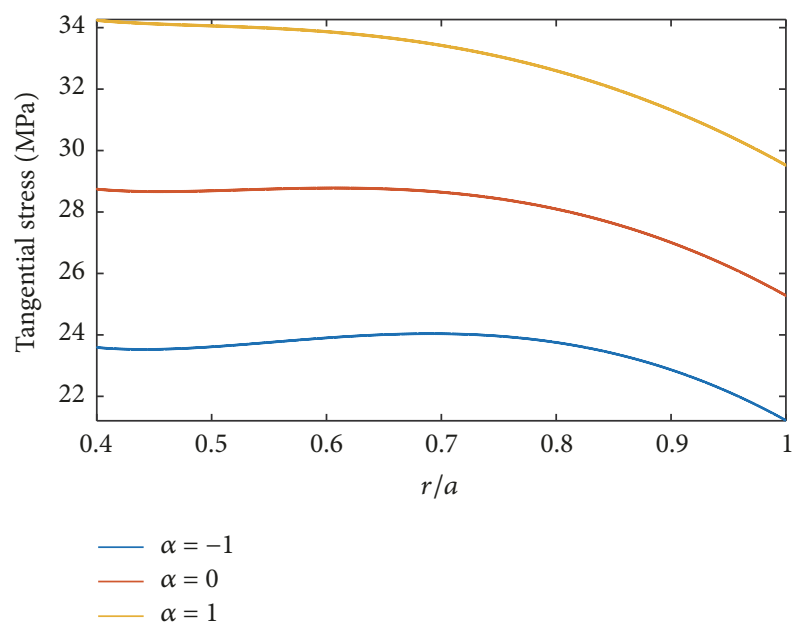

(c)

FIGURE 21: Variation of (a) radial stress, (b) radial displacement, (c) tangential stress of rotating FG plate with (F-F) boundary conditions $(n=1)$.

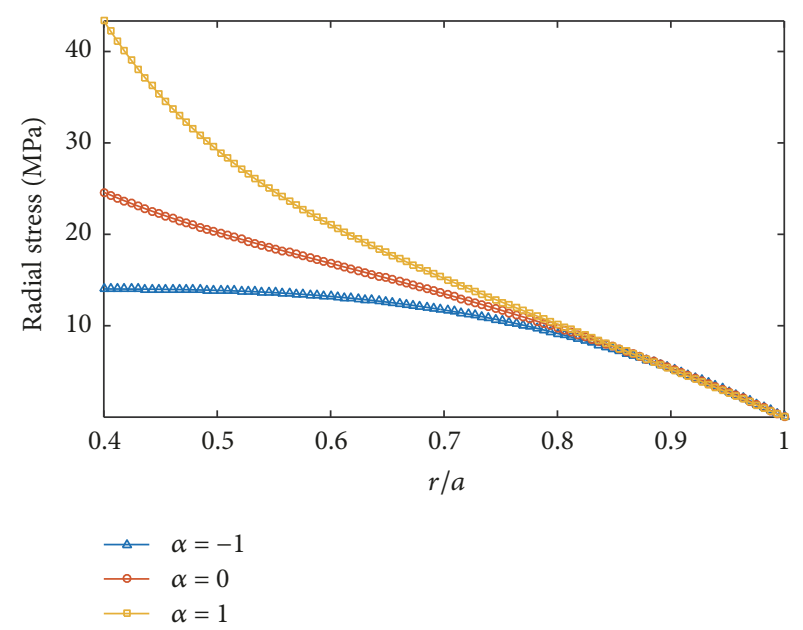

(a)

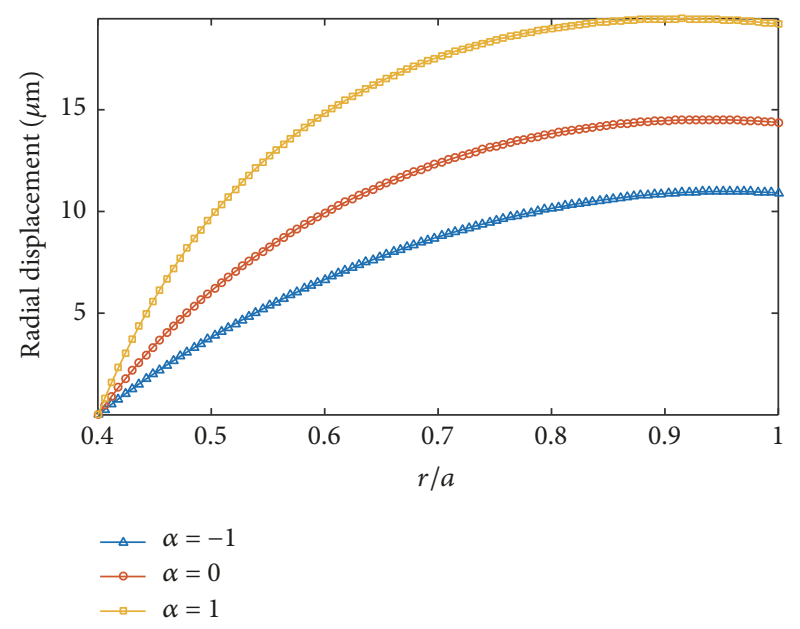

(b)

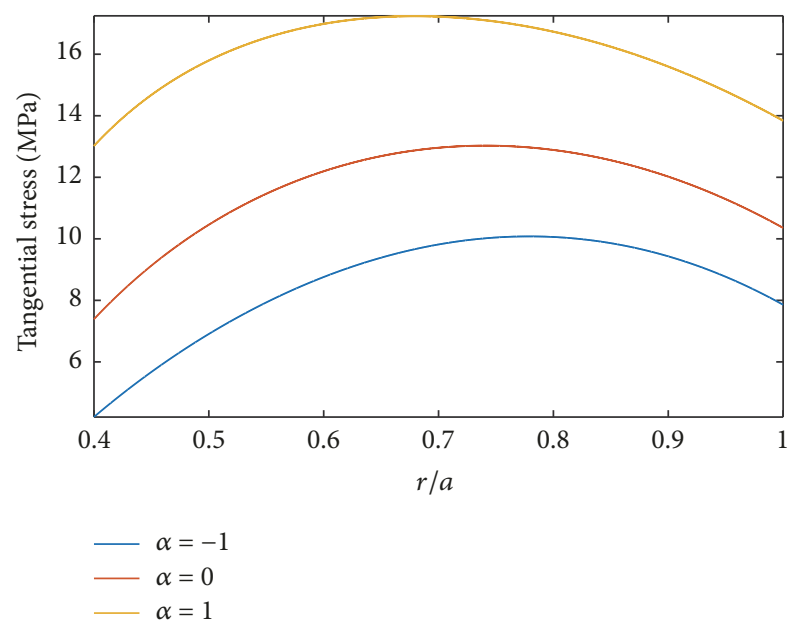

(c)

FIGURE 22: Variation of (a) radial stress, (b) radial displacement, (c) tangential stress of rotating FG plate with (C-F) boundary conditions $(n=1)$. 

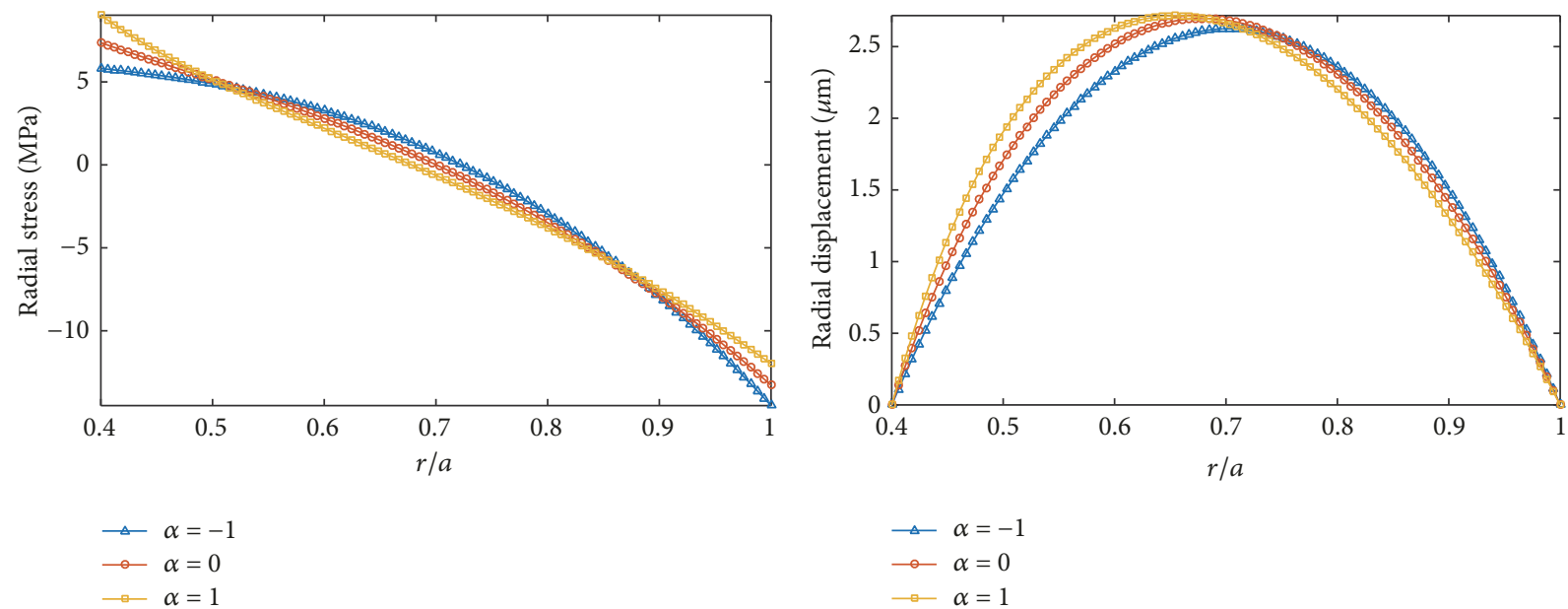

(a)

(b)

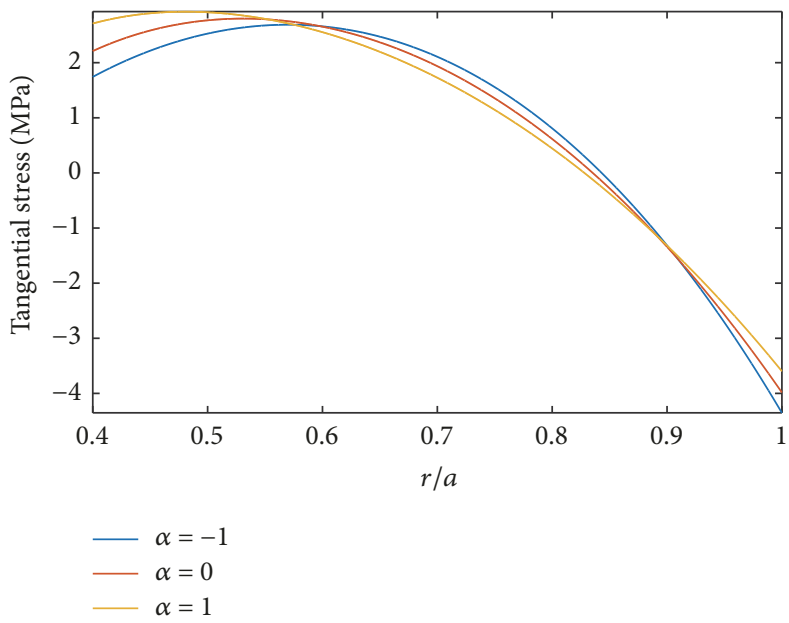

(c)

FIgURE 23: Variation of (a) Radial stress (b) Radial Displacement (c) Tangential stress of rotating FG plate with (C-C) boundary conditions $(n=1)$.

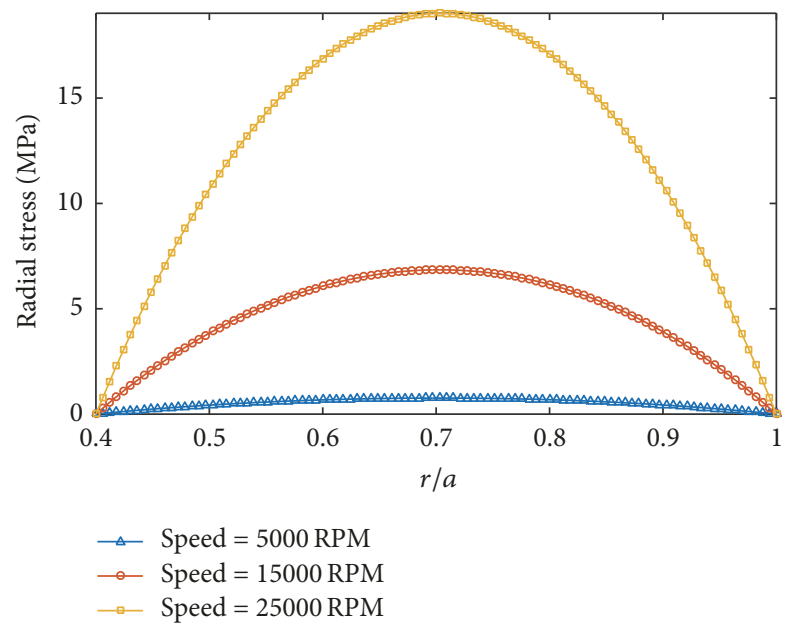

FIGURE 24: Variation of radial stress versus radius, (F-F) $(n=1$, $\alpha=-1)$.
It was also demonstrated that increasing the rotating speed can strongly increase the stress in a FG annular disk.

\section{Conflicts of Interest}

The authors declare that they have no conflicts of interest.

\section{References}

[1] M. Bayat, M. Saleem, B. B. Sahari, A. M. S. Hamouda, and E. Mahdi, "Mechanical and thermal stresses in a functionally graded rotating disk with variable thickness due to radially symmetry loads," International Journal of Pressure Vessels and Piping, vol. 86, no. 6, pp. 357-372, 2009.

[2] S.-C. Yi, L.-Q. Yao, and B.-J. Tang, "A Novel Higher-Order Shear and Normal Deformable Plate Theory for the Static, Free Vibration and Buckling Analysis of Functionally Graded Plates," Mathematical Problems in Engineering, vol. 2017, Article ID 6879508, 20 pages, 2017. 
[3] M. H. Jalali, B. Shahriari, M. Ghayour, S. Ziaei-Rad, and S. Yousefi, "Evaluation of dynamic behavior of a rotor-bearing system in operating conditions," World Academy of Science, Engineering and Technology, International Journal of Mechanical, Aerospace, Industrial, Mechatronic and Manufacturing Engineering, vol. 8, no. 10, pp. 1675-1679, 2014.

[4] M. Mohammadsalehi, O. Zargar, and M. Baghani, "Study of non-uniform viscoelastic nanoplates vibration based on nonlocal first-order shear deformation theory," Meccanica, vol. 52, no. 4-5, pp. 1063-1077, 2017.

[5] H. Lamb and R. V. Southwell, "The Vibrations of a Spinning Disk," Proceedings of the Royal Society of London. Series A, Containing Papers of a Mathematical and Physical Character, vol. 99, no. 699, pp. 272-280, 1921.

[6] R. V. Southwell, "On the Free Transverse Vibrations of a Uniform Circular Disc Clamped at Its Centre; and on the Effects of Rotation," Proceedings of the Royal Society A Mathematical, Physical and Engineering Sciences, vol. 101, no. 709, pp. 133-153, 1922.

[7] M. Deshpande and C. D. Mote, "In-plane vibrations of a thin rotating disk," Journal of Vibration and Acoustics, vol. 125, no. 1, pp. 68-72, 2003.

[8] M. Asghari and E. Ghafoori, "A three-dimensional elasticity solution for functionally graded rotating disks," Composite Structures, vol. 92, no. 5, pp. 1092-1099, 2010.

[9] H. P. Lee and T. Y. Ng, "Vibration and critical speeds of a spinning annular disk of varying thickness," Journal of Sound and Vibration, vol. 187, no. 1, pp. 39-50, 1995.

[10] B. Shahriari, M. Jalali, and M. Karamooz Ravari, "Vibration analysis of a rotating variable thickness bladed disk for aircraft gas turbine engine using generalized differential quadrature method," Proceedings of the Institution of Mechanical Engineers, Part G: Journal of Aerospace Engineering, vol. 231, no. 14, pp. 2739-2749, 2017.

[11] I. D. Kermani, H. R. Mirdamadi, and M. Ghayour, "Nonlinear stability analysis of rotational dynamics and transversal vibrations of annular circular thin plates functionally graded in radial direction by differential quadrature," Journal of Vibration and Control, vol. 22, no. 10, pp. 2482-2502, 2014.

[12] M. H. Jalali, B. Shahriari, O. Zargar, M. Baghani, and M. Baniassadi, "Free vibration analysis of rotating functionally graded annular disc of variable thickness using generalized differential quadrature method," Scientia Iranica, 2017.

[13] G. J. Nie and R. C. Batra, "Stress analysis and material tailoring in isotropic linear thermoelastic incompressible functionally graded rotating disks of variable thickness," Composite Structures, vol. 92, no. 3, pp. 720-729, 2010.

[14] H. Zafarmand and B. Hassani, "Analysis of two-dimensional functionally graded rotating thick disks with variable thickness," Acta Mechanica, vol. 225, no. 2, pp. 453-464, 2014.

[15] M. Bayat, M. Saleem, B. B. Sahari, A. M. S. Hamouda, and E. Mahdi, "Analysis of functionally graded rotating disks with variable thickness," Mechanics Research Communications, vol. 35, no. 5, pp. 283-309, 2008.

[16] H. Çallioğlu, N. B. Bektaş, and M. Sayer, "Stress analysis of functionally graded rotating discs: Analytical and numerical solutions," Acta Mechanica Sinica, vol. 27, no. 6, pp. 950-955, 2011.

[17] D. P. Gutzwiller and M. G. Turner, "Rapid low fidelity turbomachinery disk optimization," Advances in Engineering Software, vol. 41, no. 5, pp. 779-791, 2010.
[18] D. Gutzwiller, Automated design, analysis, and optimization of turbomachinery disks, University of Cincinnati, 2009.

[19] E. Carrera, A. Entezari, M. Filippi, and M. A. Kouchakzadeh, "3D thermoelastic analysis of rotating disks having arbitrary profile based on a variable kinematic 1D finite element method," Journal of Thermal Stresses, vol. 39, no. 12, pp. 1572-1587, 2016.

[20] M. A. Kouchakzadeh and A. Entezari, "Analytical solution of classic coupled thermoelasticity problem in a rotating disk," Journal of Thermal Stresses, vol. 38, no. 11, pp. 1269-1291, 2015.

[21] A. Entezari and M. A. Kouchakzadeh, "Analytical solution of generalized coupled thermoelasticity problem in a rotating disk subjected to thermal and mechanical shock loads," Journal of Thermal Stresses, vol. 39, no. 12, pp. 1588-1609, 2016.

[22] F. Vivio, V. Vullo, and P. Cifani, "Theoretical stress analysis of rotating hyperbolic disk without singularities subjected to thermal load," Journal of Thermal Stresses, vol. 37, no. 2, pp. 117136, 2014. 


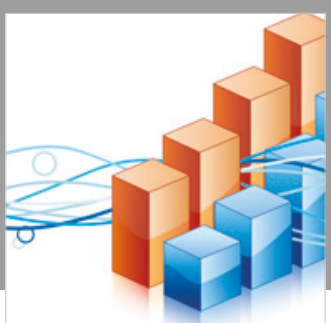

Advances in

Operations Research

\section{-n-m}
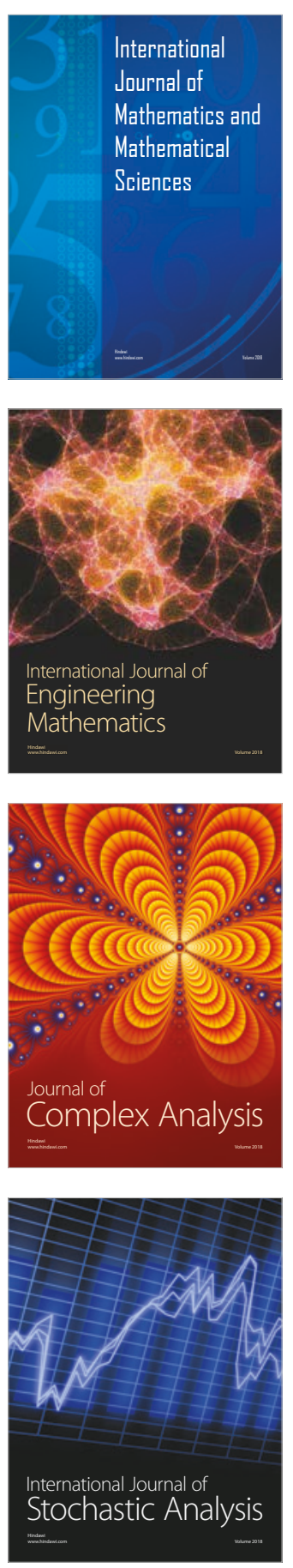
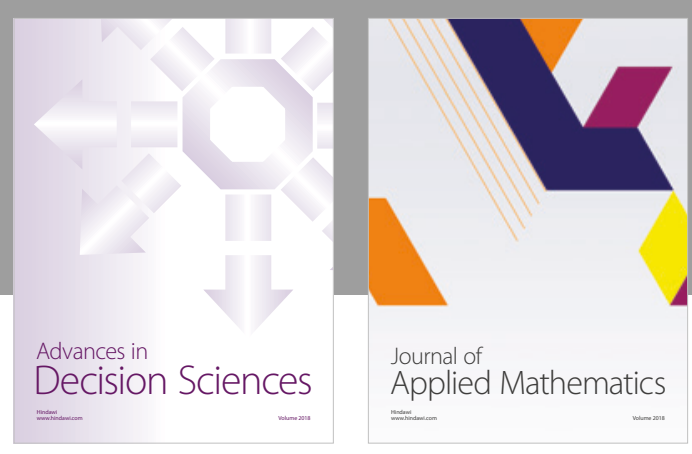

Journal of

Applied Mathematics
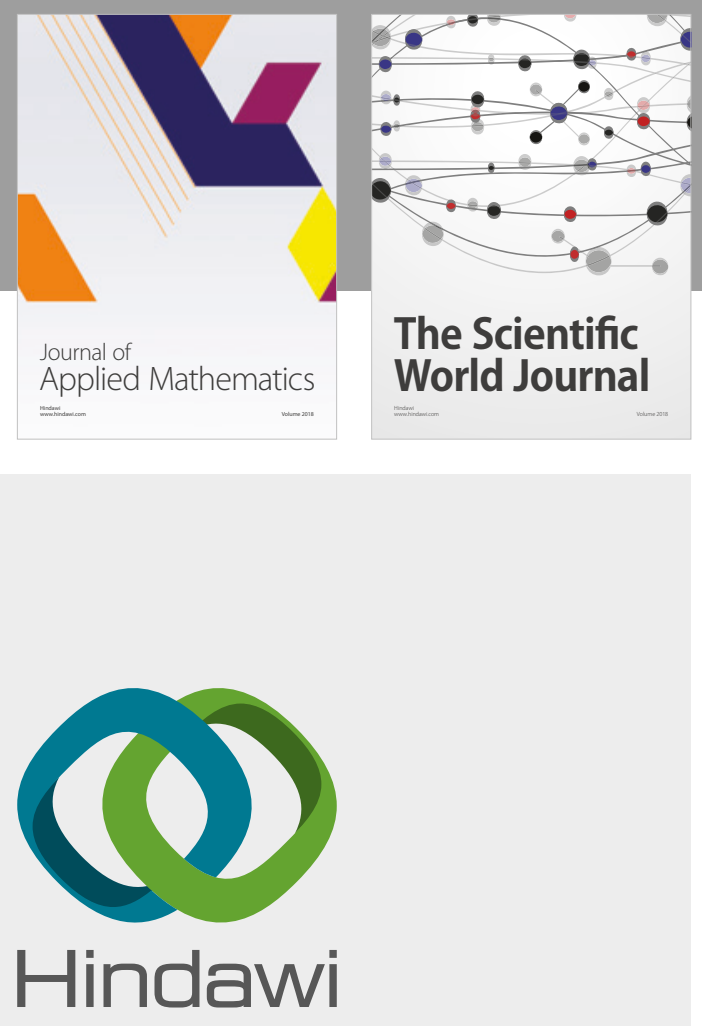

Submit your manuscripts at

www.hindawi.com

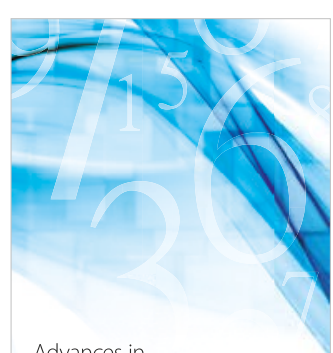

Advances in
Numerical Analysis
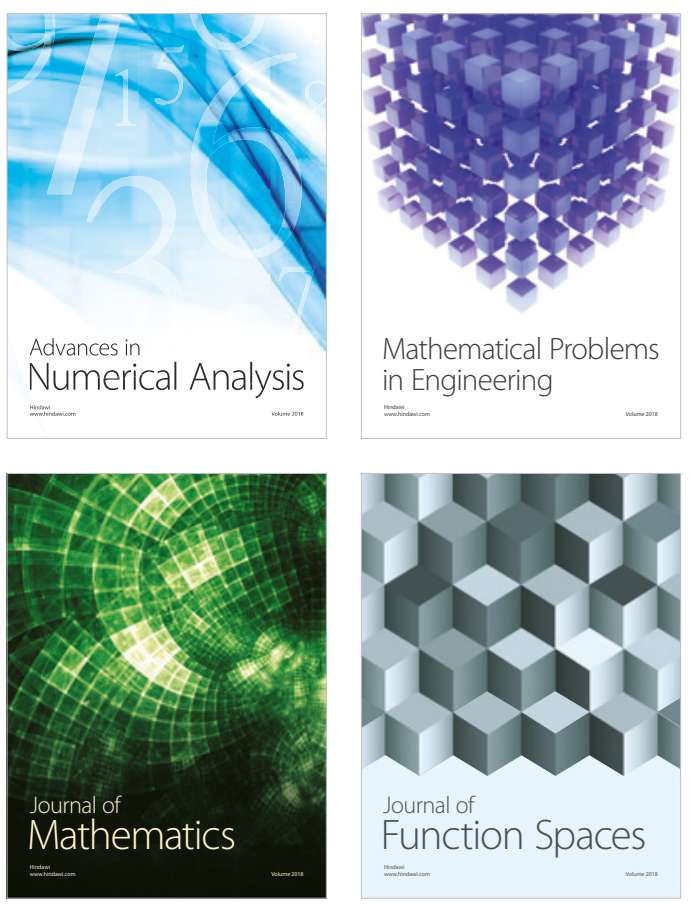

Mathematical Problems in Engineering

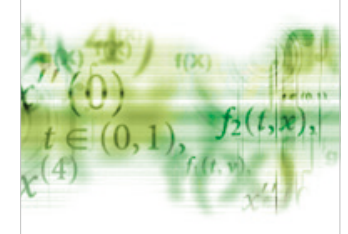

International Journal of

Differential Equations

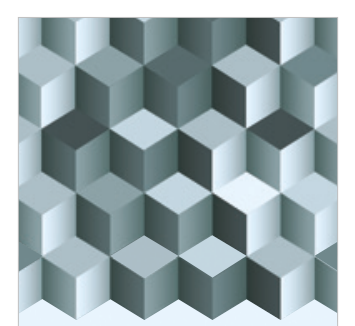

Journal of

Function Spaces

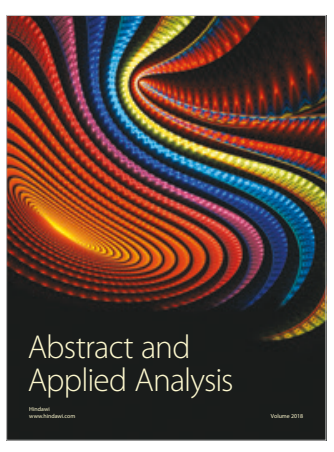

The Scientific

World Journal

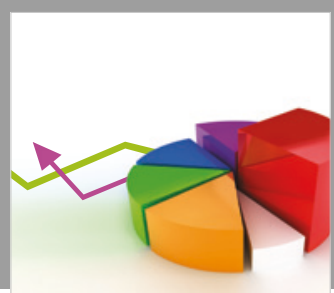

Journal of

Probability and Statistics
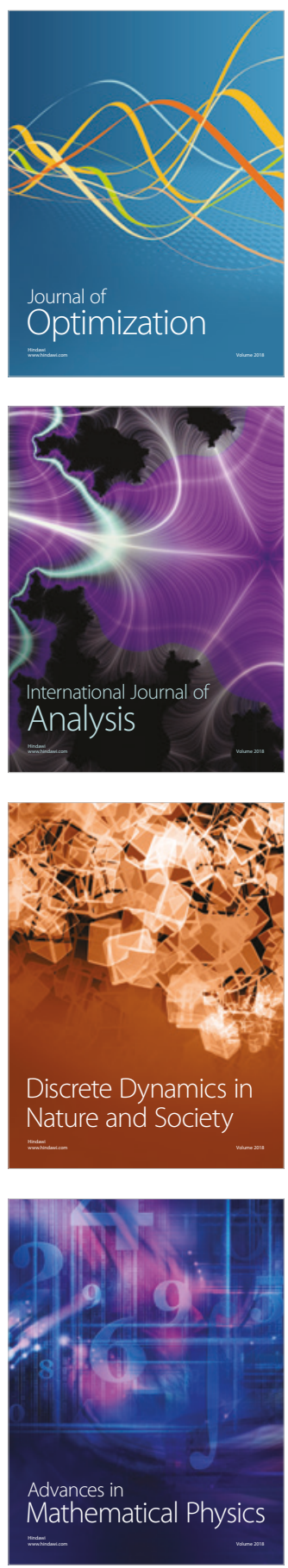